\title{
COMPARATIVE ANALYSIS OF SATELLITE MEASUREMENTS CALCULATION RESULTS USING THE POSTPROCESSING SERVICES: ASG-EUPOS (POLAND), APPS (USA) AND CSRS (CANADA)
}

\author{
Monika Mika, Jakub Kudach \\ Departament of Land Surveying \\ University of Agriculture in Krakow \\ 30-198 Kraków, ul. Balicka 253a \\ e-mail:momika@ar.krakow.pl
}

\begin{abstract}
The publication has a cognitive research character. It presents a comparative analysis of free Internet services in Poland and abroad, used to adjust the data obtained using satellite measurement techniques. The main aim of this work is to describe and compare free tools for satellite data processing and to examine them for possible use in the surveying works in Poland. Among the many European and global services three of them dedicated to satellite measurements were selected: ASG-EUPOS (Poland), APPS (USA) and CSRS (Canada). The publication contains the results of calculations using these systems. Calculations were based on RINEX files obtained via postprocessing service (ASG-EUPOS network) POZGEO D for 12 reference stations in the South Poland.

In order to examine differences in results between the ASG-EUPOS, APPS and CSRS the transformation points coordinate to a single coordinate system ETRF 2000 (in force in Poland) was made. Studies have shown the possibility of the calculation in Poland (in postprocessing mode) using the analyzed applications with global coverage.
\end{abstract}

Keywords: ASG-EUPOS, APPS , CSRS , elaboration of satellite measurements

\section{INTRODUCTION}

For many years, the measurement techniques using satellite equipment have been used globally. One can observe continuous organizational and technical measures aiming to increase the accuracy of measurement results using these techniques. This applies to both satellite measurement methods in real time and in postprocessing. Many Internet services are offering services to adjust geodetic calculations. Unfortunately, not all of them perform this service free of charge.

The aim of this study is to describe and to compare the parameters of the selected web applications, designed to elaborate a "raw" data from GNSS. These applications are available from any web browser. To comparison were selected: ASG-EUPOS (Poland), APPS (USA) and CSRS (Canada). 
These studies are an attempt to answer the question whether the accuracy of point coordinates determination obtained using global services, after appropriate transformation, are sufficient to use these services in the surveying works in Poland.

\section{THE MULTIFUNCTIONAL PRECISE SATELLITE POSITIONING SYSTEM ASG-EUPOS}

In Poland, since 2008, a nationwide network of reference stations ASG-EUPOS has been operating, which has been providing free services of adjustment of satellite observations in postprocessing mode and real-time measurements. It is an integral part of the European EUPOS system. The average distance between stations is $70 \mathrm{~km}$. To the network of reference stations existing stations EPN and IGS have been incorporated. Station coordinates are determined in the PL-ERTF2000 system. In the reference stations of Polish service solely precise, dual frequency GNSS receivers are. These stations were installed on the roofs of public buildings due to ensure their safety and to create favourable conditions for observing GNSS satellites. [www.asgeupos.pl]

Currently, there are approximately 120 reference stations throughout the Poland. For the calculations there are also used stations belonging to the positioning systems of neighbouring countries, which also work in the EUPOS system. Figure 1 shows the map with the location of these stations. The system uses mainly NAVSTAR GPS and GLONASS satellites.

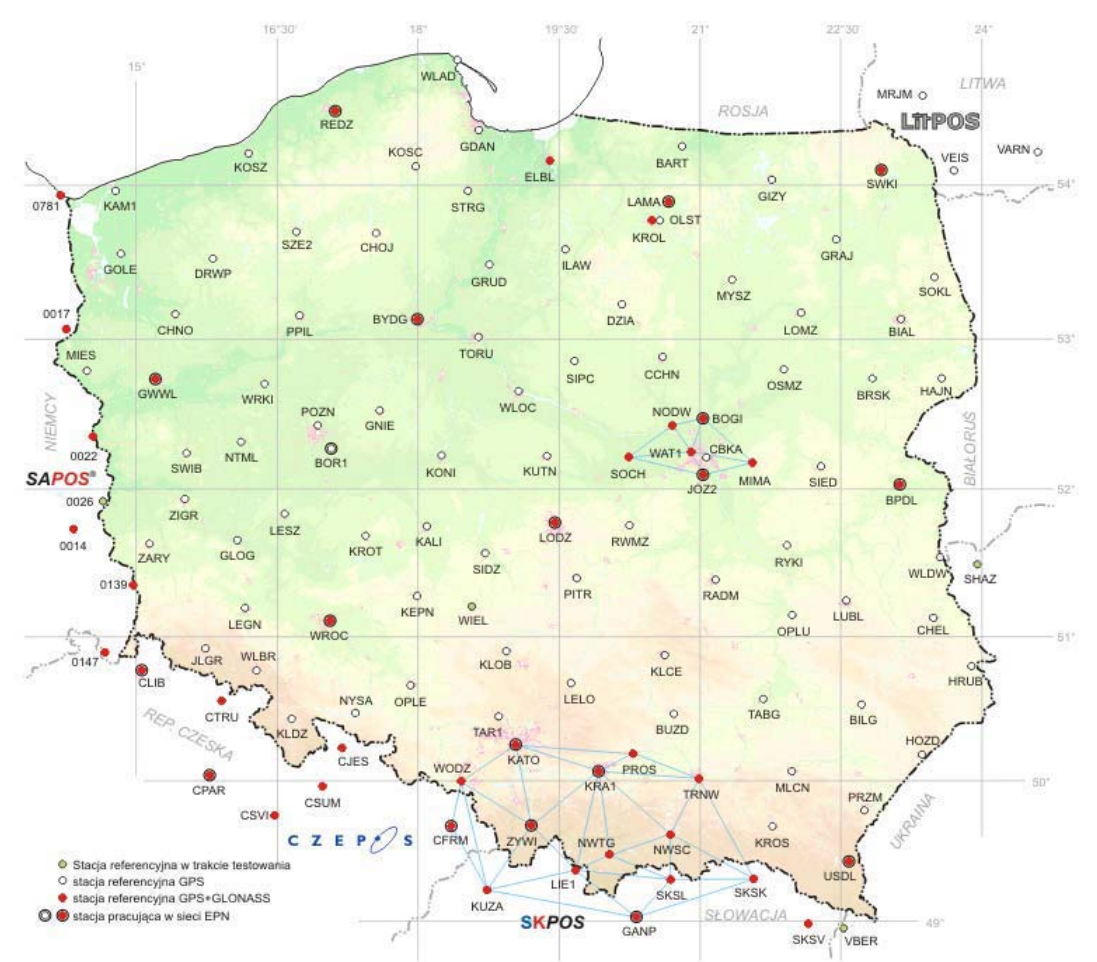

Fig. 1. Location of reference stations ASG-EUPOS

Source: http://www.asgeupos.pl 


\subsection{DESCRIPTION OF THE SYSTEM}

The main segment of the system is a receiving segment, which is responsible for collecting data and transferring them to the Computing Center. In Computing Center current data from the reference stations are automatically calculated and corrections are generated for RTK and DGPS, which next are made available to users of the system. In addition, the Managing Centre is responsible for maintaining the reference system of the state. Users are the third segment of the system. They benefit from the services of the system using receivers with communication module, usually a device with GPRS module. It is also possible to calculate the position without such a service module using postprocessing.

The accuracy of RTK / DGPS measurements decreases with increasing distance from the base station. Therefore, the system ASG-EUPOS uses surface (or network) corrections. This is possible thanks to the combination the reference stations in the network where as was mentioned before stations send GNSS to the Computing Center, where corrections are generated and made available to users. In the service NAWGEO (one of the few services available in the system) surface corrections such as MAC, VRS, FKP are available .

ASG-EUPOS system offers its users the services available so far for free. Services are divided mainly on the services of real time and postprocessing ones. These services differ from one another primarily with measurement accuracy and hardware requirements. In detail they are presented in Table 1. The main service of the system is the service NAVGEO, which is a real-time service used by surveyors in Poland. Its accuracy allows the comprehensive use of applications in the field measurements, provided one has a dual-frequency receiver and a convenient configuration of the measurement field.

Table 1. Services of the ASG-EUPOS system

\begin{tabular}{|c|c|c|c|c|c|}
\hline Type & Name & $\begin{array}{c}\text { Measurements } \\
\text { method }\end{array}$ & $\begin{array}{c}\text { Data } \\
\text { transmission }\end{array}$ & $\begin{array}{l}\text { Assumead } \\
\text { accuracy }\end{array}$ & $\begin{array}{l}\text { Minimum } \\
\text { hardware } \\
\text { requirements }\end{array}$ \\
\hline \multirow{3}{*}{$\begin{array}{l}\text { Real-Time } \\
\text { Services }\end{array}$} & NAWGEO & kinematic (RTK) & \multirow{3}{*}{$\begin{array}{c}\text { Internet, } \\
\text { GSM (GPRS) }\end{array}$} & $\begin{array}{l}\text { to } 0,03 \mathrm{~m} \text { (hor.) } \\
\text { to } 0,05 \mathrm{~m} \text { (vert.) }\end{array}$ & $\begin{array}{c}\text { Receiver L1/L2 RTK, } \\
\text { communication } \\
\text { module }\end{array}$ \\
\hline & KODGIS & \multirow{2}{*}{$\begin{array}{c}\text { Kinematic } \\
\text { (DGPS) }\end{array}$} & & to $0,25 \mathrm{~m}$ & \multirow{2}{*}{$\begin{array}{c}\text { Receiver L1 DGPS, } \\
\text { communication } \\
\text { module }\end{array}$} \\
\hline & NAWGIS & & & to $3 \mathrm{~m}$ & \\
\hline \multirow{2}{*}{$\begin{array}{l}\text { Postprocessing } \\
\text { Services }\end{array}$} & POZGEO & static & \multirow{2}{*}{ Internet } & \multirow{2}{*}{$\begin{array}{l}\text { Dependent on the } \\
\text { measurement } \\
\text { conditions } \\
(0,01-0,10 \mathrm{~m})\end{array}$} & \multirow{2}{*}{ Receiver L1 } \\
\hline & $\begin{array}{l}\text { POZGEO } \\
\text { D }\end{array}$ & $\begin{array}{l}\text { static, } \\
\text { kinematic }\end{array}$ & & & \\
\hline
\end{tabular}

Source: http://www.asgeupos.pl

The post-processing services are intended for users performing static measurements, which are characterized by high measurement precision depending on the conditions and length of the measurement sessions. Service POZGEO D allows you to download data from the reference stations in order to apply the observations to independent calculations on the user software. Due to the fact that all the calculations are performed in users own software, the user can adjust the settings to meet his requirements to a greater extent than through an application made available by the system ASG-EUPOS. All activities related to the collection of data are carried out using a web browser. 
POZGEO service offers the ability to automatically calculate the observational data from static measurements. The entire computational procedure is done through the web application and the user can set only the options available in the application.

The use of web-based ASG-EUPOS system is widely known in Poland and described in detail in a number of positions of literature [Bosy J. et al. 2007],[Kadaj R., Świętoń T. 2009], Oleniacz G. 2012],[Siejka Z. 2011], [Świątek et al. 2011],[Uznański A. 2012].. The description of the procedure available on the website of the service is more than enough for the smooth use of its features. The following description is the collection of essential information, which from the point of view of a comparative analysis taken in the paper was considered important.

Using the services of ASG-EUPOS is fully automated. For real-time services it is sufficient to enter in the receiver software appropriate options such as the port number of the selected service and the username and password obtained by registering each user of the system. In Europe, there are many similar systems [Parseliunas E. et al. 2007]. The themes of the technical details of the construction of similar networks and their applications can also be found in many references [Brockmann E. 2009],[Habrich H. 2007],[Hirt C. 2011].

\subsection{THE PROCEDURE FOR OBTAINING COMPUTING DATA}

After logging in to POZGEO D the user will find intuitive and easy to use interface with the help of which we can generate data from the physical reference station CORS or the virtual station VRS. To obtain the data, user adds order and chooses between a physical and virtual station. When choosing a physical station the user can choose available national stations that can be chosen from the list. For the purposes of this study the following stations were selected: KATO, KLCE, KRA1, KROS, LELO, NWSC, NWTG, PROS, PRZM, TABG, TRNW and ZYWI. When a station is selected, user goes to the options window that is offered by this service. The user selects here the date and time at which the measurements were performed and the interval at which he wants to get the data (available from 1 to 60 seconds). In this way the user can obtain requested data on e-mail or download them from his account after logging in the system. The time it takes to generate the ordered set of observations depends on whether at this time the service is more or less burdened by other users. There is also the possibility of failure in generating the data caused by interruptions in data collection on a particular station. Planned interruptions or failures in the operation of the station or system are described on the website of the service. When ordering, the user can select the data format in which he wants to download them, available formats are as follows: RINEX, DAT, TGD, T01, T02.

After downloading the observations a set of three files for each station is obtained. These are observational files of satellites NAVSTAR, GLONASS, file with the observations of both systems and a file with a summary of the contract which contains, inter alia, information about the: station name, date, time and duration of the session, the time of data generating, interval, the available epochs, the data format. Such data can be used in the selected programs suitable to perform the postprocessing.

On the other hand - with the help of the POZGEO service the user can transfer his data from the session of the static measurement performed by the phase method to perform calculations in postprocessing mode. The method is fully automated and access to it is possible from a form in a Web browser. Files uploaded to the service after screening the format compatibility are calculated using automated software Automatic Postprocessing Software for Trimble Application (APPS). Using the service is limited to attaching a RINEX file (ang. Receiver Independent Exchange Format) and antenna model selection in selection 
table. The user has to choose the model of the receiver antenna which actually has been used. It is also possible to take advantage of two additional options: NONE or RINEX. If option NONE is selected- any model of the antenna is not adopted in the calculations. As a result, the program will "assume" that the antenna phase center is the same as the geometric center (phase center offsets will be equal 0). As the result of this assumption, however, the results of measurements will be subject to errors reaching values up to several centimeters. In the case of the second option - RINEX - model of the antenna will be downloaded from the RINEX file header. If the model in the RINEX file will be indicated incorrectly, or not in accordance with the ANTEX format, then the model NONE will be accepted automatically [Kadaj, Świętoń 2009].

The file sent to the calculations must be in the RINEX format v2.xi and not exceed 17 MB. It should be remembered that the file sent to the calculations had RINEX v2.xi format and not exceeded $17 \mathrm{MB}$. In addition, observations must be made to the minimum of four satellites simultaneously. The duration of the measurement should be from 15 minutes to 24 hours. In turn, the number of measuring epochs should be in the range of 720 to 3600 . If the file that was send contains more than 3600 epochs, the measurement interval is automatically changed to a multiple of specified interval.

Calculations are performed with the use of the six nearest reference stations, which determined vectors satisfy the requirements of accuracy. The result of the calculation are adjusted coordinates in ETRF2000 system (European Terrestrial Reference Frame) and additionally user gets coordinates transformed to the systems used in Poland: 1992, 2000, 1965, UTM and the heights in ellipsoidal and Kronstadt 86 systems. Using this method is convenient and relatively quick, but limited in possibilities of data and the coefficients preview. Besides receiving a set of coordinates and their errors the user has no influence on the course of the calculations.

\section{AUTOMATIC PRECISE POSITIONING SERVICE OF THE GLOBAL DIFFERENTIAL GPS (GDGPS) SYSTEM.}

Automatic Precise Positioning Service (APPS) of the Global Differential GPS (GDGPS) System is a web application for the calculation of the GPS data using the Jet Propulsion Laboratory (JPL) data such as: GPS satellites orbits in real time and JPL time patterns of GDGPS system, daily and weekly precise orbits and GPS time and the JPL GIPSY-OASIS software for precise GPS measurements.

This application provides services free of charge for postprocessing of static measurements. In addition, it offers services such as generating receiver position in time series when it was in a motion, on the ground or in the air. Fig. 2 shows the locations of APPS stations. 


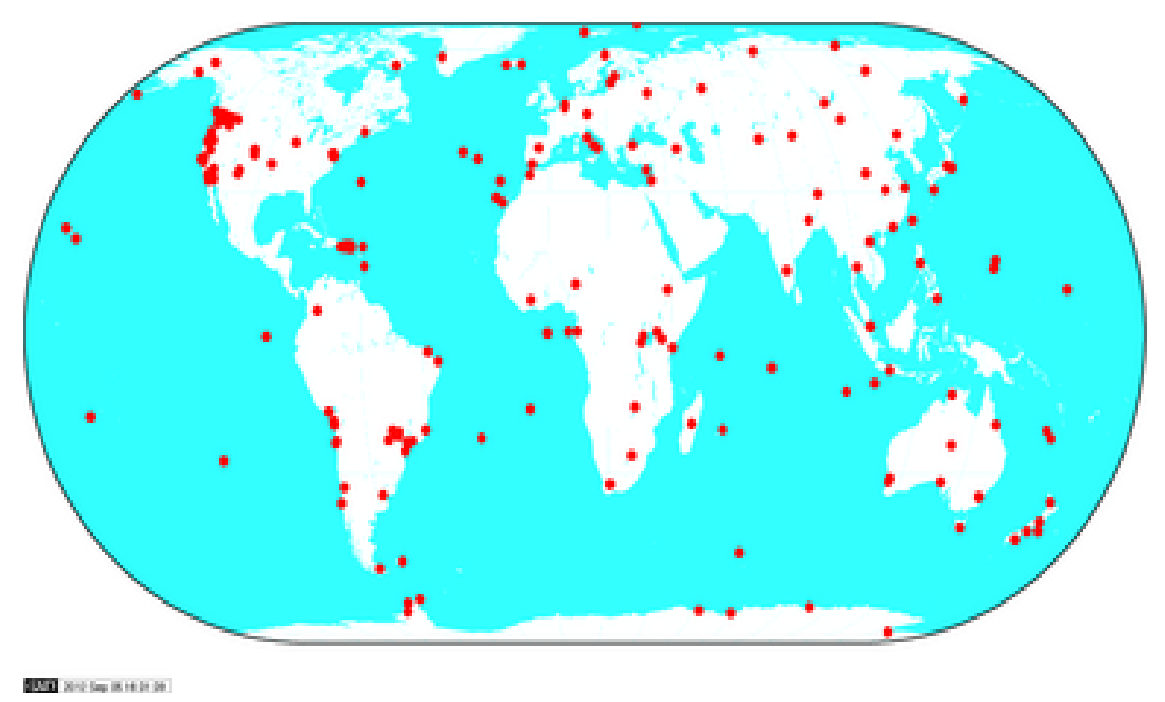

Fig. 2. The locations of APPS stations

Source: [www.apps.gdgps.net]

Global Differential GPS (GDGPS) is a system for monitoring and support of GPS, it uses the network of real-time reference receivers. It allows calculating the position in real time with the precision of $10 \mathrm{~cm}$ and a sub-nanosecond precision of data transfer anywhere on the Earth, in the air, in space - regardless of local infrastructure. GDGPS using the real-time network tracks civil frequency signals L1 and L2. Redundant satellite range provides smooth and reliable global coverage. The data from the reference stations are transmitted to one of four GDGPS Operation Centers (GOC). The data are there converted by the Real Time GIPSY (RTG) software in order to obtain real-time differential correction to the orbits of satellites and the GPS time. The basis of the GDGPS network is the Global GPS NASA Network. The owner and operator of some 70 high-quality dual frequency receivers located around the world is the JPL. Additional positions of receivers are made available by many U.S. and international partner organizations, which gives about 100 stations (data from 2006). At one time, each satellite is observed on average in the 25 locations, the minimum redundancy is 10 .

Using a variety of data transmission channels to operating centers, including Internet, VPN (Virtual Private Network)), satellite transmissions and Frame Relay (packet-switched network used to connect remote LANs) causes a system delay about five seconds. Sending data to the operating center takes about one second, the remaining time is used for data processing and data quality control.

As in the Polish ASG-EUPOS, to use the Automatic Precision Positioning Service (APPS) it is necessary to log on this service site (http://apps.gdgps.net). This application supports files of the RINEX Version 2 or 2.11 with any file name and a minimum interval of one second. It is possible to send files from static and kinematic measurements. APPS offers four modes of data processing, which are a combination of two methods: static and kinematic. It also offers two options for delay: Near Real Time and Most Accurate

Static - static mode where it is assumed that the receiver remains in place without moving, so it will generate one set of coordinates of the site.

Kinematic - kinematic mode where it is assumed that the receiver can be in motion therefore a series of coordinates in the default or lower time interval is generated. 
Near Real Time mode -provides the fastest response APPS from the moment of measurement. The best available GPS orbits and time data at the moment of measurement are used. If the measurement was made no later than one day prior to the date of data dispatch for the calculations - they will be processed using the data from the system GDGPS. Based on these data RMS ang. Root Mean square error can be obtained less than $8 \mathrm{~cm}$ for User Range Error (URE) which is the distance measurement error. For measurements older than 1 day but younger than one week data will be calculated on the GPS Rapid Jet Propulsion Laboratory orbit. These products provide a measurement error of $5 \mathrm{~cm}$ RMS. After one week, it is possible to elaborate data for GPS Final orbit created like the Rapid orbits by NASA's Jet Propulsion Laboratory. These are the most accurate GPS satellite orbits provided by JPL and they give a measurement error of less than $3 \mathrm{~cm}$ RMS.

Most Accurate in APPS application are data obtained one week after the measurement when the GPS Final orbits are available for the best accuracy.

Using the APPS web application is possible after the registration of the user on the website www.apps.gdgps.net. In the "Instant Positioning" overlap there is a simple to use interface which is shown in Figure 3.

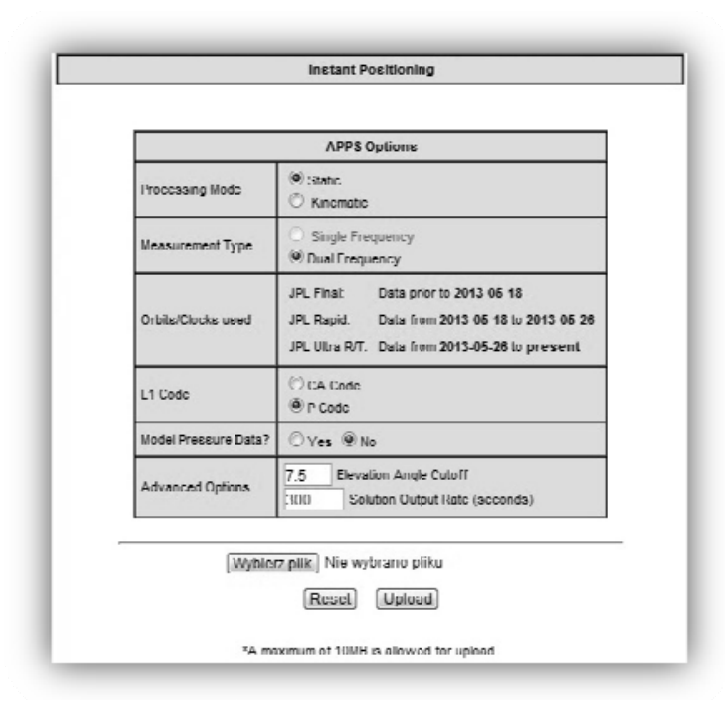

Fig. 3. APPS web application interface

Source: https://apps.gdgps.net/apps/apps_file_upload.php

Maximum size of observations file cannot exceed 10MB. The static calculation results are accessible from the browser. They can be downloaded directly from the website (Fig. 4). The kinematic calculation data are sent to the e-mail address provided by the user. 


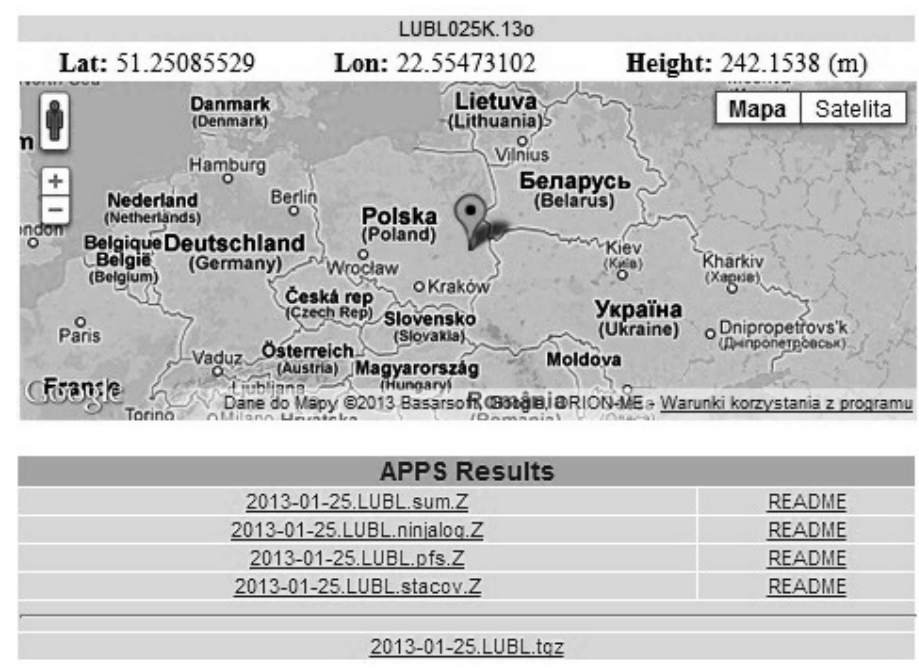

Fig. 4. Calculation results download panel on APPS website.

Source: http://apps.gdgps.net

Figure 4 presents the results window with calculation results. It can be used to read geodetic coordinates of the calculated point and preview point location on an interactive map. The results can be downloaded separately by clicking on the links below the map or in a package. A README file is provided for each results file, explaining its content. The ".sum" file sums up the calculations. The headers are preceded with a hash symbol. The part that follows contains tabular information. The header contains information such as: input filename, calculation duration, time interval, horizon cutoff angle, navigation orbit details, number of phase and pseudodistance measurements, as well as the number of rejected measurements and estimated receiver coordinates in both Cartesian and geodetic coordinate systems.

It should be remembered that all calculations performed by APPS application are made in the ITRF2008 system.

\section{CANADIAN SPATIAL REFERENCE SYSTEM (CSRS)}

Canadian Spatial Reference System (CSRS) is managed by Geodetic Survey Division (GSD) of Natural Resources Canada (NRCan's). It is resposible for the Canadian reference system including parameters of the Earth's orientation and rotational velocity and for the development of positioning and navigation in Canada. CSRS also provides other products, such as:

- RINEX file postprocessing with use of Canadian Active Control Points (ACP), which can be related to Polish reference stations network.

- GPS satellite ephemeris files generated with use of Canadian and foreign reference stations with use of ULTRA RAPID orbits.

- High-precission 3D reference point network (The Canadian Base Network - CBN) distributed on the territory of Canada as pillars with an option of instrument forced centering, used as the highest precision reference points.

- The Canadian Gravity Standardization Net (CGSN) is a network of gravitational reference stations, distributed uniformly around Canada.

- The Canadian Geodetic Vertical Datum of 1928 (GCVD28.) is a network of elevation reference points, located along main communication routes in Canada. 
- Northern Horizontal Control Network (2D) is a network of horizontal reference points established using various (non-satellite) methods of medium precission, located in the northern part of Canada, 20 to 100 kilometers apart.

CSRS consists of a network of points, whose coordinates are precisely determined, what constitutes Canadian network. CSRS includes "subnetworks" of various precision and application, from the basic ACP network, through traditional CBN network to Gravity Reference Stations (GRS).

The Canadian Base Network was established in the year 1994. It consists of points located on permanent pillars on which measurement instruments can be installed with forced centering. Precise measurement of the pillars with use of GPS allows to use CBN points to monitor land deformation and to verify the reference system in Canada. It has one centimeter precision of point with respect to the Canadian Active Point System (CAPS) and is its densification. The points are located $200 \mathrm{~km}$ apart on the south, $500 \mathrm{~km}$ apart in the middle and $1000 \mathrm{~km}$ apart in the north of Canada. Figure 5 presents the locations of CACS stations.

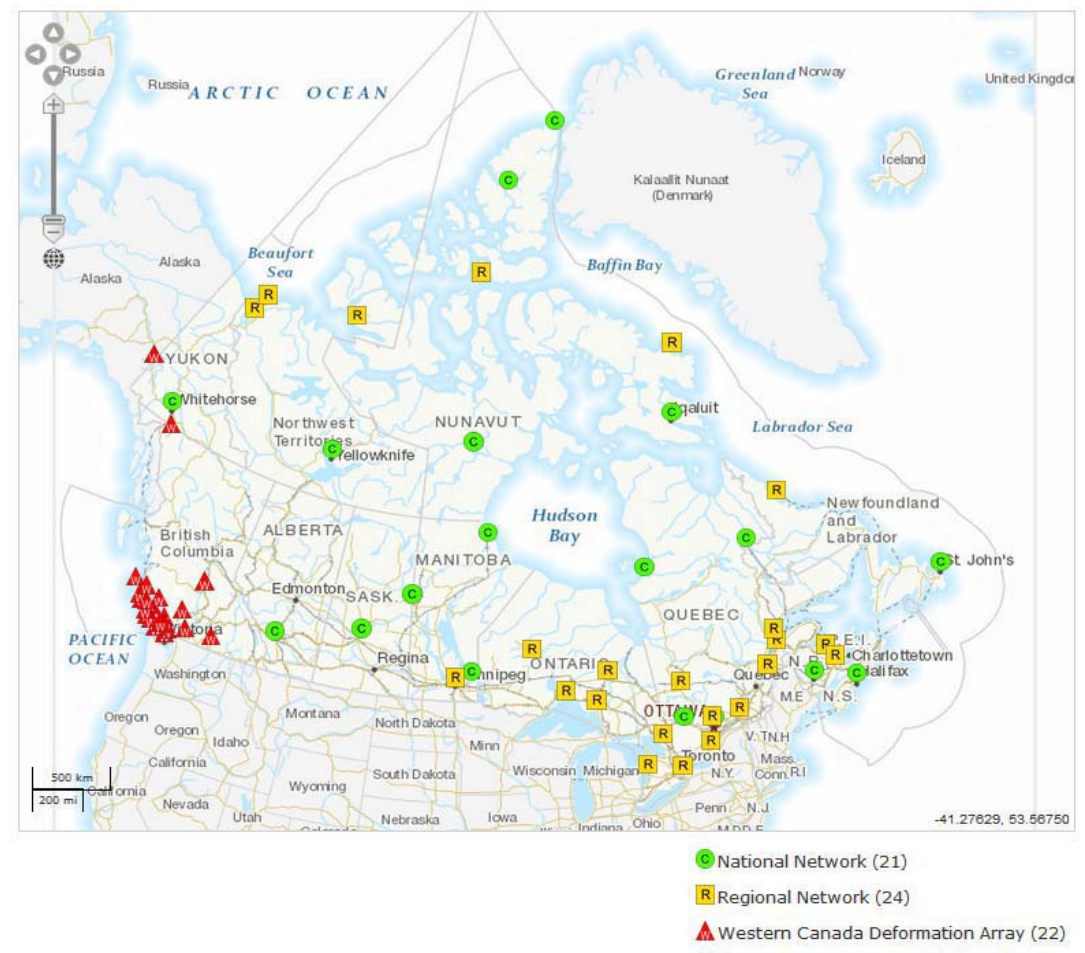

Fig. 5. Location of CACS stations

Source [webappp.geod.nrcan.gc.ca/geod/csrs]

Introduction of GPS in the 1980s resulted in creation of Geodetic Survey Division of the Canadian Active Control System (CACS), whose purpose was to track GPS satellites and to calculate their precise orbits. The Canadian Active Control System consists of reference points all over the country which gather GPS data, used for calculation of precise orbits of the satellites, which can be later used nationwide and worldwide. Additionally, for GPS users the data is available for free and can be used as base station data for various differential measurements in postprocessing. The data is available in RINEX format with 30 second interval. Availability of precise ephemeris and atomic time standard allows to determine the position with high precision not only in Canada, but also all over the world, depending on the influence of interference and multipath at the place of measurement. Thanks to the use of precise ephemeris calculated by CACS it is possible to reduce the errors related to the 
determination of satellite orbits to $0.1 \mathrm{ppm}$ (parts per million). In the case when ephemeris are received directly from the satellites this error can exceed $3 \mathrm{ppm}$. CACS data are also used by The International GNSS Service (IGS). In CACS also functions a computational center which allows sharing the data with international organizations, such as International Earth Rotation Service (IERS), NASA Crustal Dynamics Data Information System (CDDIS), US National Geodetic Survey (USNGS).

Precise ephemeris of GPS satellites and corrections from atomic clocks are being calculated based on the data collected by CACS and IGS reference stations worldwide. Canada owns one of ten data centers which take part in calculation of precise ephemeris of the satellites.

The calculations performed by CSRS-PPP ${ }^{1}$ web application use the most precise ephemeris available at the moment of calculations. Thanks to the ephemeris prepared in this way, and to the precise time standard it is possible for this application to perform calculations based on statistical measurements with precision of a few centimeters (for any location worldwide). To achieve high precision it is required to use dual-frequency receivers for measuring sessions taking at least 12 hours (Tab.3).

Table 3 Horizontal accuracy of the point determination using CSRS-PPP

\begin{tabular}{|c|c|c|}
\hline & $2-3$ hours of observation & $12-24$ hours of observation \\
\hline $\begin{array}{c}\text { Static CSRS-PPP } \\
\text { Dual-frequency receiver }\end{array}$ & $<5 \mathrm{~cm}$ & $<1 \mathrm{~cm}$ \\
\hline $\begin{array}{c}\text { Static CSRS-PPP } \\
\text { Single-frequency receiver }\end{array}$ & $<50 \mathrm{~cm}$ & not applicable \\
\hline
\end{tabular}

Source: http://www.nrcan.gc.ca/earth-sciences/geography-boundary/spatial-referencing/about-spatial-referencing/5240

The Canadian Spatial Reference System does not allow downloading corrections in real time (RTK). It offers for the users to determine the position in space with centimeter precision with use of the postprocessing software which can be opened in a browser. The application and access to large amounts of data is free and available for anyone after registration on the website: www.nrcan.gc.ca. For the convenience of the users, PPP Direct software was developed. It offers the same possibilities as the browser application, but it does not require the user to $\log$ in. The calculation results are automatically sent to the e-mail address provided by the user.

While using the CSRS-PPP post processing application, the user has to provide the path to RINEX file which contains raw measurement data. For users' convenience, the panel contains information regarding file preparation. Next, the user selects the method and system in which the results will be provided. One can choose between ITRF (International Terrestrial Reference Frame) and NAD83 (North American Datum). After selecting the system, the user provides e-mail address, to which the calculations will be sent, and clicks "START". The whole process is automatic and the results can be downloaded from the e-mail inbox. Parameters, such as observation interval, antenna type and height, as well as approximate coordinates, are automatically imported from the RINEX file.

\footnotetext{
${ }^{1}$ The web application is available on the website of the Canadian Department of Natural Resources NRCan which is described further below.
} 
The data e-mailed to the user contain four files which give an insight into the quality of gathered data. They include

- „*.sum” ${ }^{2}$ text file, containing a summary

- „*.pos” text file, containing station parameters for each epoch in the session

- "*.csv" file, containing the calculated coordinates for each epoch in the session

- „ ".pdf" file, containing the summary and graphical interpretation

Data prepared in this way serves as a source of huge amount of information regarding the measurement session and calculations. It should be noted, that static session observations allow using kinematic calculations, which can be used to evaluate the position divergence in time. In the opposite case, using kinematic session in option of static calculations, the most of observations will be rejected because of too much divergence from the mean position. For advanced users, the prepared data can be a source for data for analyses of precision, signal quality and more. For an average user, the data can also be very useful, however only a part of it is needed. The reports are a source of knowledge regarding the quality of acquired data. Figure 6 presents exemplary graphical reports for each measurement modes.

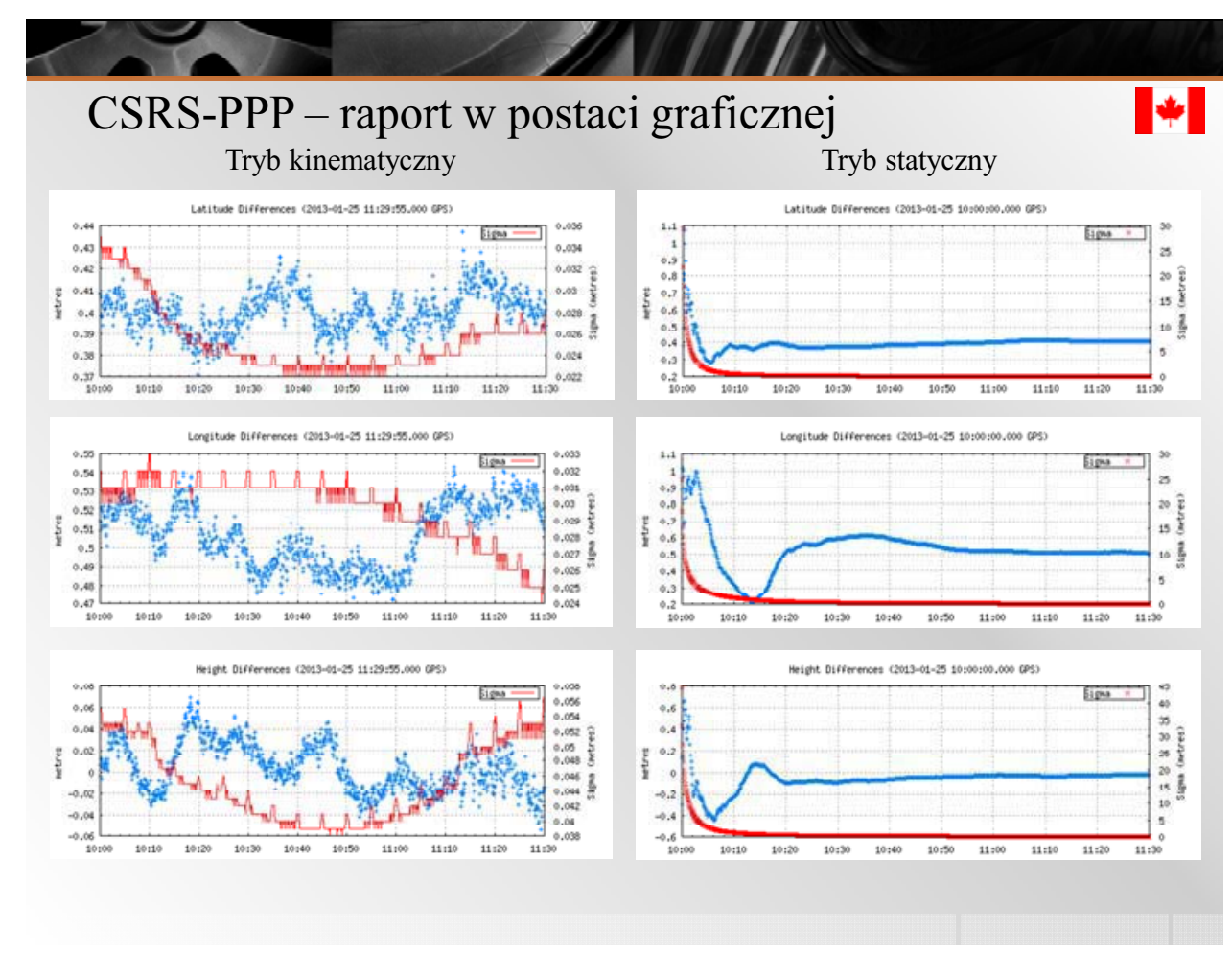

Fig. 6. Exemplary CSRS reports

[Source Own elaboration]

\footnotetext{
${ }^{2}$ Files are named by adding the appropriate input file name extension. Here "*" is the name of the file
} 


\section{COMPARISON OF INTERNET SERVICES: ASG-EUPOS, APPS AND CSRS}

Table 4 presents comparison of discussed internet applications according to selected criteria.

Table 4. Comparison of Internet applications

\begin{tabular}{|c|c|c|c|}
\hline & ASG-EUPOS & APPS & CSRS-PPP \\
\hline Country of origin & Poland & United States of America & Canada \\
\hline $\begin{array}{l}\text { Applied satellite } \\
\text { systems }\end{array}$ & $\begin{array}{l}\text { NAVSTAR GPS } \\
\text { partially GLONASS }\end{array}$ & NAVSTAR GPS & $\begin{array}{l}\text { NAVSTAR GPS } \\
\text { GLONASS }\end{array}$ \\
\hline $\begin{array}{l}\text { Measurement } \\
\text { methods }\end{array}$ & $\begin{array}{l}\text { Post processing of static } \\
\text { measurements } \\
\text { RTK, RTN }\end{array}$ & $\begin{array}{l}\text { Post processing of static } \\
\text { and kinematic } \\
\text { measurements }\end{array}$ & $\begin{array}{l}\text { Post processing of static and } \\
\text { kinematic measurements }\end{array}$ \\
\hline Correction method & $\begin{array}{l}\text { Observational corrections } \\
\text { with respect to the positions } \\
\text { of reference stations - } \\
\text { differential method }\end{array}$ & $\begin{array}{l}\text { Corrections with respect } \\
\text { to satellite orbits and } \\
\text { time standard }\end{array}$ & $\begin{array}{l}\text { Corrections with respect to } \\
\text { satellite orbits and time } \\
\text { standard }\end{array}$ \\
\hline Spatial limitations & $\begin{array}{l}\text { Area limited to Poland's } \\
\text { territory and its immediate } \\
\text { vicinity due to the } \\
\text { limitations with respect to } \\
\text { distance from ground-based } \\
\text { reference stations }\end{array}$ & $\begin{array}{l}\text { Measurements possible } \\
\text { worldwide both on the } \\
\text { entire Earth and in the air }\end{array}$ & $\begin{array}{l}\text { Measurements possible } \\
\text { worldwide both on the entire } \\
\text { Earth and in the air }\end{array}$ \\
\hline Reference systems & ETRF2000 & ITRF2008 & ITRF2008/NAD83 \\
\hline $\begin{array}{l}\text { Achieved precision in } \\
\text { static coordinate } \\
\text { determination }\end{array}$ & $\begin{array}{l}\text { Horizontally: } 0.005 \mathrm{~m} \\
\text { Vertically: } 0.017 \mathrm{~m} \\
\begin{array}{l}\text { From the ASG-EUPOS } \\
\text { report }\end{array}\end{array}$ & $\begin{array}{l}\text { Horizontally: } 0.024 \mathrm{~m} \\
\text { Vertically: } 0.012 \mathrm{~m} \\
\text { From the APPS report }\end{array}$ & $\begin{array}{l}\text { Horizontally: } 0.055 \mathrm{~m} \\
\text { Vertically: } 0.066 \mathrm{~m} \\
\text { From the CSRS report }\end{array}$ \\
\hline
\end{tabular}

Source [Own elaboration]

In order to compare the coordinates acquired for 12 selected reference stations, they were transformed into the Polish ETRF2000 coordinate system, with use of software available on the following website: http://www.epncb.oma.be/_productsservices/coord trans/.

Table 5 lists the coordinates in own coordinate systems of the following applications: ASG-EUPOS (ETRF2000), APPS (ITRF2008), CSRS (ITRF2008).

Table 6 presents the coordinates after APPS transformation from ITRF2008 to the uniform coordinate system obligatory in Poland (ETRF2000).

Table 7 presents differences between ASG-EUPOS and APPS in ETRF2000 system.

Table 8 presents the coordinates after CSRS transformation from ITRF2008 to the uniform coordinate system obligatory in Poland (ETRF2000).

Table 9. presents the differences between ASG-EUPOS and CSRS coordinates in ETRF2000 system. 
Table 5. Coordinates in the own coordinate systems ASG-EUPOS (ETRF2000), APPS (ITRF2008), CSRS (ITRF2008)

\begin{tabular}{|c|c|c|c|c|}
\hline Station & AXIS & ASG-EUPOS & APPS & CSRS \\
\hline \multirow[t]{3}{*}{ KATO } & $\mathrm{X}$ & 3862992.369 & 3862991.9106 & 3862991.8883 \\
\hline & $\mathrm{Y}$ & 1332822.662 & 1332823.0409 & 1332823.0117 \\
\hline & $\mathrm{Z}$ & 4881105.429 & 4881105.7202 & 4881105.6963 \\
\hline \multirow[t]{3}{*}{ KLCE } & $\mathrm{X}$ & 3774368.87 & 3774368.3598 & 3774368.3763 \\
\hline & $\mathrm{Y}$ & 1420921.168 & 1420921.4987 & 1420921.5293 \\
\hline & $\mathrm{Z}$ & 4925093.013 & 4925093.277 & 4925093.2841 \\
\hline \multirow[t]{3}{*}{ KRA1 } & $\mathrm{X}$ & 3856938.911 & 3856938.4436 & 3856938.4319 \\
\hline & $\mathrm{Y}$ & 1397750.204 & 1397750.6051 & 1397750.5579 \\
\hline & $\mathrm{Z}$ & 4867717.329 & 4867717.6299 & 4867717.5898 \\
\hline \multirow[t]{3}{*}{ KROS } & $\mathrm{X}$ & 3840336.495 & 3840336.0112 & 3840335.9924 \\
\hline & $\mathrm{Y}$ & 1534053.84 & 1534054.2196 & 1534054.2055 \\
\hline & $\mathrm{Z}$ & 4840009.362 & 4840009.6549 & 4840009.6365 \\
\hline \multirow[t]{3}{*}{ LELO } & $\mathrm{X}$ & 3814251.01 & 3814250.5051 & 3814250.5131 \\
\hline & $\mathrm{Y}$ & 1360360.152 & 1360360.4774 & 1360360.4963 \\
\hline & $\mathrm{Z}$ & 4911504.885 & 4911505.1452 & 4911505.1447 \\
\hline \multirow[t]{3}{*}{ NWSC } & $\mathrm{X}$ & 3873461.75 & 3873461.2963 & 3873461.2424 \\
\hline & $\mathrm{Y}$ & 1462888.133 & 1462888.5305 & 1462888.4823 \\
\hline & $\mathrm{Z}$ & 4835656.003 & 4835656.3108 & 4835656.2617 \\
\hline \multirow[t]{3}{*}{ NWTG } & $\mathrm{X}$ & 3901050.87 & 3901050.4253 & 3901050.3868 \\
\hline & $\mathrm{Y}$ & 1422373.035 & 1422373.4373 & 1422373.4048 \\
\hline & $\mathrm{Z}$ & 4826032.3 & 4826032.6075 & 4826032.5719 \\
\hline \multirow[t]{3}{*}{ PROS } & $\mathrm{X}$ & 3837829.029 & 3837828.5464 & 3837828.5113 \\
\hline & $\mathrm{Y}$ & 1418779.896 & 1418780.2632 & 1418780.2441 \\
\hline & $\mathrm{Z}$ & 4876685.613 & 4876685.8906 & 4876685.8664 \\
\hline \multirow[t]{3}{*}{ PRZM } & $\mathrm{X}$ & 3804695.692 & 3804695.1747 & 3804695.189 \\
\hline & $\mathrm{Y}$ & 1595660.815 & 1595661.1662 & 1595661.1846 \\
\hline & $\mathrm{Z}$ & 4848106.466 & 4848106.7433 & 4848106.7457 \\
\hline \multirow[t]{3}{*}{ TABG } & $\mathrm{X}$ & 3772239.483 & 3772238.9706 & 3772238.9809 \\
\hline & $\mathrm{Y}$ & 1498958.697 & 1498959.0521 & 1498959.0561 \\
\hline & $\mathrm{Z}$ & 4903535.39 & 4903535.6552 & 4903535.659 \\
\hline \multirow[t]{3}{*}{ TRNW } & $\mathrm{X}$ & 3834315.764 & 3834315.2807 & 3834315.2593 \\
\hline & $\mathrm{Y}$ & 1470638.338 & 1470638.7111 & 1470638.6954 \\
\hline & $\mathrm{Z}$ & 4864150.724 & 4864151.0077 & 4864150.9915 \\
\hline \multirow[t]{3}{*}{ ZYWI } & $\mathrm{X}$ & 3904633.318 & 3904632.8462 & 3904632.8297 \\
\hline & $\mathrm{Y}$ & 1360191.867 & 1360192.2358 & 1360192.2354 \\
\hline & $\mathrm{Z}$ & 4840630.766 & 4840631.0498 & 4840631.0459 \\
\hline
\end{tabular}


Table 6. Comparison of ASG-EUPOS (ETRF2000) and APPS coordinates after the transformation from ITRF2008 to ETRF2000

\begin{tabular}{|c|c|c|c|c|c|c|c|c|c|}
\hline \multirow{3}{*}{ Station } & \multirow{2}{*}{\multicolumn{3}{|c|}{$\begin{array}{c}\text { ASG-EUPOS } \\
\text { PL-ERTF2000 (epoka 2011.0) }\end{array}$}} & \multirow{2}{*}{\multicolumn{6}{|c|}{ Results after APPS transformation and means errors }} \\
\hline & & & & & & & & & \\
\hline & $\mathbf{X}$ & $\mathbf{Y}$ & $\mathbf{Z}$ & $\mathbf{X}_{\mathbf{t}}$ & $\mathbf{Y}_{\mathrm{t}}$ & $\mathbf{Z}_{\mathrm{t}}$ & $\mathbf{m x}$ & my & $\mathbf{m z}$ \\
\hline KATO & 3862992.369 & 1332822.662 & 4881105.429 & 3862992.3320 & 1332822.7179 & 4881105.4582 & 0.0210 & -0.0127 & -0.0081 \\
\hline KLCE & 3774368.870 & 1420921.168 & 4925093.013 & 3774368.7907 & 1420921.1830 & 4925093.0203 & 0.0215 & -0.0124 & -0.0077 \\
\hline KRA1 & 3856938.911 & 1397750.204 & 4867717.329 & 3856938.8689 & 1397750.2812 & 4867717.3673 & 0.0216 & -0.0119 & -0.0073 \\
\hline KROS & 3840336.495 & 1534053.840 & 4840009.362 & 3840336.4469 & 1534053.8991 & 4840009.3955 & 0.0219 & -0.0125 & -0.0078 \\
\hline LELO & 3814251.010 & 1360360.152 & 4911504.885 & 3814250.9301 & 1360360.1583 & 4911504.8858 & 0.0213 & -0.0126 & -0.0078 \\
\hline NWSC & 3873461.750 & 1462888.133 & 4835656.003 & 3873461.7259 & 1462888.2071 & 4835656.0491 & 0.0216 & -0.0127 & -0.0079 \\
\hline NWTG & 3901050.870 & 1422373.035 & 4826032.300 & 3901050.8510 & 1422373.1113 & 4826032.3440 & 0.0214 & -0.0127 & -0.0080 \\
\hline PROS & 3837829.029 & 1418779.896 & 4876685.613 & 3837828.9747 & 1418779.9425 & 4876685.6306 & 0.0213 & -0.0126 & -0.0080 \\
\hline PRZM & 3804695.692 & 1595660.815 & 4848106.466 & 3804695.6158 & 1595660.8485 & 4848106.4861 & 0.0222 & -0.0123 & -0.0076 \\
\hline TABG & 3772239.483 & 1498958.697 & 4903535.390 & 3772239.4070 & 1498958.7369 & 4903535.3992 & 0.0217 & -0.0124 & -0.0077 \\
\hline TRNW & 3834315.764 & 1470638.338 & 4864150.724 & 3834315.7125 & 1470638.3907 & 4864150.7481 & 0.0216 & -0.0125 & -0.0078 \\
\hline ZYWI & 3904633.318 & 1360191.867 & 4840630.766 & 3904633.2676 & 1360191.9094 & 4840630.7858 & 0.0211 & -0.0128 & -0.0082 \\
\hline
\end{tabular}

Table 7. Differences between ASG-EUPOS and APPS in ETRF2000 system

\begin{tabular}{|l|r|r|r|r|}
\hline \multirow{2}{*}{ Station } & \multicolumn{5}{|c|}{$\begin{array}{c}\text { Differences between coordinates after } \\
\text { transformation }\end{array}$} & $\begin{array}{c}\text { Displacement } \\
\text { vector }\end{array}$ \\
\cline { 2 - 6 } & dx & \multicolumn{1}{|c|}{ dy } & \multicolumn{1}{c|}{ dz } & \multicolumn{1}{c|}{ dp } \\
\hline KATO & 0.037 & -0.056 & -0.029 & 0.073 \\
\hline KLCE & 0.079 & -0.015 & -0.007 & 0.081 \\
\hline KROS & 0.042 & -0.077 & -0.038 & 0.096 \\
\hline LELO & 0.048 & -0.059 & -0.033 & 0.083 \\
\hline NWSC & 0.080 & -0.006 & -0.001 & 0.080 \\
\hline NWTG & 0.024 & -0.074 & -0.046 & 0.091 \\
\hline PROS & 0.019 & -0.076 & -0.044 & 0.090 \\
\hline PRZM & 0.054 & -0.046 & -0.018 & 0.074 \\
\hline TABG & 0.076 & -0.034 & -0.020 & 0.086 \\
\hline TRNW & 0.076 & -0.040 & -0.009 & 0.086 \\
\hline ZYWI & 0.052 & -0.053 & -0.024 & 0.078 \\
\hline Mean & 0.050 & -0.042 & -0.020 & 0.069 \\
\hline Standard deviation & $\mathbf{0 . 0 2 1}$ & $\mathbf{0 . 0 2 3}$ & $\mathbf{0 . 0 1 5}$ & $\mathbf{0 . 0 0 8}$ \\
\hline Mean error & $\mathbf{0 . 0 5 9}$ & $\mathbf{0 . 0 5 5}$ & $\mathbf{0 . 0 2 9}$ & $\mathbf{0 . 0 8 6}$ \\
\hline
\end{tabular}


Table 8. Comparison of ASG-EUPOS (ETRF2000) and CSRS coordinates after the transformation from ITRF2008 to ETRF2000

\begin{tabular}{|c|c|c|c|c|c|c|c|c|c|}
\hline \multirow{3}{*}{ Station } & \multicolumn{3}{|c|}{ ASG-EUPOS } & \multirow{2}{*}{\multicolumn{6}{|c|}{ Results after CSRS transformation and means errors }} \\
\hline & \multicolumn{3}{|c|}{ PL-ERTF2000 (epoka 2011.0) } & & & & & & \\
\hline & $\mathbf{X}$ & $\mathbf{Y}$ & $\mathbf{Z}$ & $\mathbf{X}_{\mathbf{t}}$ & $\mathbf{Y}_{\mathbf{t}}$ & $\mathbf{Z}_{\mathrm{t}}$ & $\mathbf{m x}$ & my & $\mathbf{m z}$ \\
\hline KATO & 3862992.369 & 1332822.662 & 4881105.429 & 3862992.2525 & - 1332822.6265 & 4881105.3840 & 0.0485 & 0.0172 & 0.0161 \\
\hline KLCE & 3774368.870 & 1420921.168 & 4925093.013 & 3774368.6766 & | 1420921.0807 & 4925092.9284 & 0.0843 & 0.0515 & 0.0399 \\
\hline KRA1 & 3856938.911 & 1397750.204 & 4867717.329 & 3856938.7983 & 31397750.1633 & 4867717.2742 & 0.0499 & 0.0221 & 0.0182 \\
\hline KROS & 3840336.495 & 1534053.840 & 4840009.362 & 3840336.3162 & 21534053.7783 & 4840009.2962 & 0.0757 & 0.0388 & 0.0311 \\
\hline LELO & 3814251.010 & 1360360.152 & 4911504.885 & 3814250.8313 & $3 \mid 1360360.0684$ & 4911504.8032 & 0.0726 & 0.0397 & 0.0317 \\
\hline NWSC & 3873461.750 & 1462888.133 & 4835656.003 & 3873461.6173 & $3|1462888.0956|$ & 4835655.9484 & 0.0479 & 0.0177 & 0.0169 \\
\hline NWTG & 3901050.870 & 1422373.035 & 4826032.300 & 3901050.7586 & | 1422373.0191 & 4826032.2586 & 0.0473 & 0.0160 & 0.0159 \\
\hline PROS & 3837829.029 & 1418779.896 & 4876685.613 & 3837828.8860 & | 1418779.8614 & 4876685.5553 & 0.0471 & 0.0172 & 0.0166 \\
\hline PRZM & 3804695.692 & 1595660.815 & 4848106.466 & 3804695.5211 & $1 \quad 1595660.7634$ & 4848106.4091 & 0.0746 & 0.0375 & 0.0306 \\
\hline TABG & 3772239.483 & 1498958.697 & 4903535.390 & 3772239.3108 & $8 \mid 1498958.6363$ & 4903535.3221 & 0.0729 & 0.0379 & 0.0312 \\
\hline TRNW & 3834315.764 & 1470638.338 & 4864150.724 & 3834315.6375 & 51470638.3139 & 4864150.6810 & 0.0474 & 0.0169 & 0.0167 \\
\hline ZYWI & 3904633.318 & 1360191.867 & 4840630.766 & 3904633.1927 & $7 \mid 1360191.8471$ & 4840630.7317 & 0.0492 & 0.0170 & 0.0159 \\
\hline
\end{tabular}

Table 9. Differences between ASG-EUPOS and CSRS coordinates in the ETRF2000 system

\begin{tabular}{|c|c|c|c|c|}
\hline \multirow{2}{*}{ Station } & \multicolumn{3}{|c|}{$\begin{array}{c}\text { Differences between coordinates after } \\
\text { transformation }\end{array}$} & \multirow{2}{*}{$\begin{array}{l}\begin{array}{c}\text { Displacement } \\
\text { vector }\end{array} \\
\text { dp }\end{array}$} \\
\hline & dx & dy & dz & \\
\hline KATO & 0.117 & 0.035 & 0.045 & 0.130 \\
\hline KLCE & 0.193 & 0.087 & 0.085 & 0.228 \\
\hline KRA1 & 0.113 & 0.041 & 0.055 & 0.132 \\
\hline KROS & 0.179 & 0.062 & 0.066 & 0.200 \\
\hline LELO & 0.179 & 0.084 & 0.082 & 0.214 \\
\hline NWSC & 0.133 & 0.037 & 0.055 & 0.148 \\
\hline NWTG & 0.111 & 0.016 & 0.041 & 0.120 \\
\hline PROS & 0.143 & 0.035 & 0.058 & 0.158 \\
\hline PRZM & 0.171 & 0.052 & 0.057 & 0.187 \\
\hline TABG & 0.172 & 0.061 & 0.068 & 0.195 \\
\hline TRNW & 0.126 & 0.024 & 0.043 & 0.136 \\
\hline ZYWI & 0.125 & 0.020 & 0.034 & 0.131 \\
\hline Mean & 0.160 & 0.050 & 0.063 & 0.165 \\
\hline Standard deviation & 0.030 & 0.023 & 0.016 & 0.038 \\
\hline Mean error & 0.269 & 0.032 & 0.042 & 0.342 \\
\hline
\end{tabular}

\section{CONCLUSIONS}

The scope of the study covered testing all of the described applications on 12 RINEX files acquired from POZGEO D service of ASG-EUPOS system.

The obtained results prove the attainment of declared precisions in the scope of information given on the websites of APPS and CSRS on the results of direct calculations. However, after transformation of the results to the ETRF 2000 system from ITRF2008 the obtained differences of the points coordinates were of the order of centimeters and decimeters, and the vectors of points in the individual coordinate systems and their errors were as follows: 
- The average displacement vector for the transformed points from ITRF 2008 APPS to ETRF 2000 amounts to $0,082 \mathrm{~m}$, and its components are $\mathrm{dx}=0,053 \mathrm{~m}$, $d y=-$ $0,048 \mathrm{~m}, \mathrm{dz}=-0,024 \mathrm{~m}$.

- The average displacement vector for the transformed points from ITRF 2008 CSRS to ETRF 2000 amounts to $0,165 \mathrm{~m}$, and its components are $\mathrm{dx}=0,147 \mathrm{~m}, \mathrm{dy}=0,046 \mathrm{~m}$, $\mathrm{dz}=0,057 \mathrm{~m}$.

- Mean error of the displacement vector between the coordinates from ASG-EUPOS and from APPS amounts to $\mathrm{mdp}=0,083 \mathrm{~m}$ and its components are $\mathrm{mx}=0,057 \mathrm{~m}$, $m y=0,053 \mathrm{~m}$ a $\mathrm{mz}=0,028 \mathrm{~m}$.

- Mean error of the displacement vector between the coordinates from ASG-EUPOS and from CSRS amounts to $\mathrm{mdp}=0,169 \mathrm{~m}$ and its components are $\mathrm{mx}=0,015 \mathrm{~m}$, $\mathrm{my}=0,051 \mathrm{~m}$ a $\mathrm{mz}=0,059 \mathrm{~m}$.

The greatest error affects the results of the transformation of the observations adjusted in the application CSRS (this applies in particular to the differences of the results obtained in ASG-EUPOS in the horizontal plane, where $\mathrm{dx}=0.160 \mathrm{~m}$ ). The reason for this situation may be the fact of adoption to data calculations the observations based on static measurements executed in less time than was recommended in CSRS (Table 3). In addition, the reason for discrepancies may be the distribution of the CSRS stations only within Canada, and not globally as is the case of the APPS stations.

The main advantage of using ASG-EUPOS, APPS and CSRS application is that they are free and public. Foreign applications have many features in common, using them is intuitive and takes as much time as ASG-EUPOS. In many cases of geodetic works, use of such software can minimize the costs and time as well as offer an alternative should ASG-EUPOS stop offering free services. The applications are fully automatic and run in an internet browser.

Usefulness of APPS and CSRS in the geodetic works in Poland seems to be possible, but not to the same extent of the use of both services and using them in the works of lower accuracy. The results of this test indicate greater suitability of calculations with the use of the APPS than with the CSSR under our latitude. Research in this direction will be continued, and presented in this publication are only partial results of the pilot character.

Preliminary studies of differences determined points coordinates showed that all services meet the precision conditions which they declared but are not fully suited to adjustment of static measurements in Poland. Perhaps prolonged time of the observations would be beneficial for the final results. These studies will be continued in the future.

Knowledge regarding the tested applications can be also useful due to the fact, that modern land surveyor should be ready to rapid and distant changes of the workplace. It is possible, that applications such as APPS or CSRS-PPP, in such situations, will be useful in adjustment of land surveying tasks from static measurements in postprocessing mode.

\section{REFERENCES}

Bosy J., Graszka W. and M. Leonczyk (2007) ASG-EUPOS Multifunctional System of Precise Satellite Positioning .London, United Kingdom, June 06-09 2007, EUREF Publication No. 17, Mitteilungen des Bundesamtes für Kartographie und Geodäsie, Band 42, pp. 174-177.

Brockmann E. (2009) Monitoring of official national ETRF coordinates on EPN web Project of the EUREF TWG. Presented at EUREF 2009 symposium, Florence, Italy, May 27-30 2009. 
Kadaj R., Świętoń T. (2009). Algorytm i oprogramowanie modułu automatycznego postprocessingu (apps) w polskim systemie satelitarnych stacji referencyjnych (asgeupos). Zeszyty Naukowe Politechniki Rzeszowskiej Nr 262, z 51.pp. 137.

Hirt C.2011 (2008) Assessment of EGM 2008 over Germany using accurate quasigeoid heights from vertical deflections, GCG05 and GPS/levelling. Zeitschrift für Geodäsie, Geoinformation und Landmanagement (zfv) 136(3): pp. 138-149.

Kadaj R. (2008) New algorithms of GPS post-processing for multiple baseline models and analogies to classical geodetic network. Geodesy and Cartography (PL), Vol. 57, No 2, 2008, pp. 61-79.

Habrich H. (2007) Updated Options and New Products of EPN Analysis London, United Kingdom, June 06-09 2007, EUREF Publication No. 17, Mitteilungen des Bundesamtes für Kartographie und Geodäsie, Band 42, pp. 82-85.

Oleniacz G. (2012) Analiza efektów zastapienia punktów nawiązania klasycznej poziomej osnowy szczegółowej III klasy wektorami do stacji systemu ASG-EUPOS. Infrastruktura i Ekologia Terenów Wiejskich. Nr 2012/ 01 (2 (Jun 2012)), pp.207-217.

Siejka Z. (2010) Ocena faktycznej dokładności wyznaczenia współrzędnych punktów geodezyjnych $\mathrm{w}$ trybie postprocessingu $\mathrm{z}$ zastosowaniem serwisów POZGEO i POZGEO-D. Infrastruktura i Ekologia Terenów Wiejskich. Nr 2010/ 06, pp.125-131.

Świątek A., Jaworski L., Zdunek R. and J. B. Zieliński (2011) Preliminary results of the GNSS Campaign integration of the ASG-EUPOS permanent stations with first order national geodetic networks. Presented at EUREF 2011 symposium, Chisinau, Republic of Moldova, May 25-28 2011

Parseliunas E., Buga A., Marozas L., Petniunas M. and Urbanas S. (2007) LitPOS - a Part of EUPOS. London, United Kingdom, June 06-09 2007, EUREF Publication No. 17, Mitteilungen des Bundesamtes für Kartographie und Geodäsie, Band 42, pp. 105-117.

Uznański A. (2012) Analiza precyzji i dokładności pozycjonowania punktów na bazie serwisu NAWGEO systemu ASG-EUPOS. Infrastruktura i Ekologia Terenów Wiejskich. Nr 2012/ 01 (2 (Jun 2012), pp. 93-103.

www.asgeupos.pl

http://apps.gdgps.net

http://webapp.geod.nrcan.gc.ca/geod/csrs

Received: 2014-03-27,

Reviewed: 2014-04-16, by W. Pyka,

Accepted: 2014-04-16. 